\title{
Pragmatic Failures in Intercultural Communication of Chinese Foreign Language Learners
}

Weixuan Shi ${ }^{1}$, Wenqian $\mathrm{Li}^{2}$

${ }^{1}$ Professor in School of Foreign Languages, North China Electric Power University, NO 689 Road, North District, Baoding, Hebei, China

${ }^{2}$ Graduate Student in School of Foreign Languages, North China Electric Power University, NO 689 Road, North District, Baoding, Hebei, China

*Corresponding author: Wenqian $\mathrm{Li}$

\section{Abstract}

With the advancement of economic globalization, intercultural communication has gradually become a practical need. From the perspective of intercultural communication, this article takes specific examples to analyze the embodiment of the pragmatic failures in daily life, including pragma-linguistic failure and socio-pragmatic failure. After summarizing the manifold reasons of pragmatic failures in intercultural communication, this article attribute pragmatic failures more too cultural differences. The significance of this article is to help students face the problems that appear frequently in intercultural communication, and help them effectively avoid pragmatic failures, thus greatly improving the competence of Chinese students to use English to communicate.

Keywords: Intercultural communication, pragma-linguistic failure, socio-pragmatic failure.

Copyright @ 2019: This is an open-access article distributed under the terms of the Creative Commons Attribution license which permits unrestricted use, distribution, and reproduction in any medium for non-commercial use (NonCommercial, or CC-BY-NC) provided the original author and source are credited.

\section{INTRODUCTION}

In economy globalization times, especially with China's accession to the WTO, China's external contacts are becoming more and more frequent, and people have more opportunities to communicate in English. Accordingly, there is no doubt that intercultural communication, as the interaction among people with different cultural backgrounds, has turned into a practical need. It is inevitable that cultural differences in such intercultural interaction may contribute to communication barriers. This kind of communication barriers caused by cultural differences might lead to more serious consequences than improper use of grammar or inaccurate pronunciation. Therefore, as for Chinese EFL learners, effectively evading the obstacles caused by cultural differences can help them successfully achieve intercultural communication.

However, foreign language teaching in China has always been placed in an embarrassing situation. On the one hand, teachers toil tirelessly in the classroom for teaching English, and students learn English after class to cope with various exams; on the other hand, even for those students with excellent academic performance, when they deal with foreigners, they find it difficult to fluently express themselves in English which they have laboriously learned for more than decades. Inevitably there will still exist pragmatic failures in external exchanges, despite that students speak English fluently. In addition, Chinese students rarely own the opportunity to acquire this language directly from the English environment. Due to the lack of pragmatic competence, students often utter some inappropriate words by mistake in the process of intercultural communication, inadvertently hurting the feeling of the others. Consequently, sometimes they are considered as rude or uncultivated. Beyond all doubt, this pragmatic failure will give rise to interruption of communication and will affect the realization of the communicative purpose.

Therefore, it is meaningful to study the phenomenon and causes of pragmatic failures in intercultural communication among Chinese students. It can help students face the problems that frequently appear in intercultural communication and help them effectively avoid pragmatic failures, thus greatly improving the Chinese students' English communicative competence.

\section{LITERATURE REVIEW}

The concept "pragmatic failure" was proposed by British scholar Jenny Thomas in 1983. The linguist Thomas [1] believes that pragmatic failure refers to that the hearer "cannot understand the meaning of the speaker's discourse content". In communication, 
pragmatic failures arise as long as the utterance meaning that hearer perceives is not equal to the real intention [1]. According to Leech [2], the common pragmatics includes pragma-linguistics and sociopragmatics. Inspired from Leech, Tomas also divides pragmatic failures into two categories: pragmalinguistic failure and socio-pragmatic Failure. Pragmalinguistic failure occurs when the speaker's pragmatic effect on a particular discourse is systematically contrary to the general understanding of the native speakers of the target language, or when certain speech act strategies are inappropriately transferred from one language to another. In contrast, socio-pragmatic failure involves different understandings about appropriate speech act [1]. However, the distinction between the two types of pragmatic failures is not absolute; owing to different contexts, it is possible that the utterances, intentions and understandings toward each other's utterances may be totally different. Therefore, an inappropriate utterance may be a pragma-linguistic failure from one perspective; but from another perspective, it may be a socio-pragmatic failure [3].

For more than 30 years, a raft of scholars at home and abroad has studied the pragmatic failures from various stages: theoretical construction, theoretical description, partial questioning to quantitative empirical research, which have obtained a series of valuable research results. Considerably, those research results can promote the exploration of fields of intercultural communication, pragmatic competence, foreign language pragmatics teaching and second language acquisition. It confirms that the theory of pragmatic failure possesses theoretical guiding significance and practical value.

In addition, many scholars have carried out relevant researches on the pragmatic competence of Chinese EFL learners and proposed corresponding measures to improve their pragmatic competence. In order to provide students with enough input of pragmatic knowledge in English classroom teaching [4, 5, 1], Bao Xiaoying and Qian Mingdan [6] came up with the "teaching material-teacher-teaching" trinity mode in the practice of interpreting teaching. That is, the teaching materials should increase the input of real pragmatic knowledge. Teachers should entrench the concept of improving students' pragmatic English ability and construct a situational teaching mode that simulates real life scenes. Lu Jiawei [7] explored the role of classroom pragmatic teaching in the cognitive framework on the development of learners' secondlanguage pragmatic competence. The conclusion is that the pragmatic competence of L2 learners is generally unsatisfactory. Social pragmatic competence may be the focus of future pragmatic research [8], which also provides new ideas for continuing to extend the study of pragmatic failures.

\section{Performance of pragmatic failures in intercultural communication Pragma-linguistic failure}

Pragma-linguistic failure, as mentioned above, is the expression mode in which learners of foreign language gloss over the context of language use, violate language habits and blindly employ their native language. For Chinese foreign language learners, pragma-linguistic failure mainly includes the following aspects:

\section{First language transfer}

The theory of transfer in language learning holds that people who learn the second language apt to transfer the rules and expressions of their native language to the use of second language. As is wellknown, Chinese students mainly learn English on the basis of mastery of Chinese. Inevitably, the process of learning English is influenced by first language and other known knowledge and experience [9].

"Of course" is a phrase commonly used in English and can be employed to answer various questions. It not only expresses enthusiasm, but also induces different psychological reactions of listeners in different contexts. This is exactly what Chinese students often make mistakes. For example, a foreign tourist came to China and asked the passerby: "Shall I take this way?" The passerby replied: "Of course." In Chinese, it can translate as “当然”. Although affirmative in English, it is coupled with underlying impatience in it. Such an answer appears to be very blunt, which carries the feeling of contempt, and the other party will think that the respondent is dismissive. The correct and proper answer should be "Yes" or "Certainly". In English, words like authorities, propaganda, politician, statesman, etc. have strong derogatory and commendatory meaning. We must consider their targets and contexts, and cannot use them arbitrarily by virtue of dictionary interpretation.

“您辛苦了。” This sentence is widely used in China. It is not appropriate to say "You've had a hard time" or "You've gone through a lot of hardships" in English, and sometimes it will cause misunderstanding. For someone who has returned over a long trip, we can say "You must have had a tiring journey" or "You must be tired from a long trip". For those who have just completed a difficult task, we can say "Well done! That was a hard job" or "You've got a hard job". The expression "You've had a hard time" or "You've gone through a lot of hardships" mechanically applies the Chinese “您辛苦了”, which is not suitable in English.

\section{Violation of language habits}

Although Chinese students understand some of the language rules of English, they often misuse the expression of English. There is no doubt that the language habits of English native speakers can be violated and the communicative effect is affected either. 
Example 1: Teacher: Jim, have you finished your homework?

Jim: Yes, I have finished my homework.

Notwithstanding there is no error from the grammatical point of view, it does not conform to the English expression habits, thus contributing to the misinterpretation that the speaker is relatively impatient. The appropriate and correct statement should be: "Yes, I have. /No, I haven't."; that is to say; the abbreviated version is more pertinent.

Example 2: A: Thank you for your help. B: Never mind.

"Never mind." is used to comfort the other party if you don't mind when the other party apologize to you. In the dialogue responding to thanks, the suitable answer to B here should be "You're welcome" or "It's my pleasure". "Never mind" obviously does not conform to the expression habits of the English language. Although the other party may understand what you mean, he will still feel uncomfortable about it.

\section{Lack of mitigations}

English native speakers often choose mitigations to ease the propositional content of the discourse so that the discourse is more acceptable to the hearer. However, Chinese students who learn English rarely digest this method; hence, their language behavior is usually too straightforward and difficult to be accepted. notes?"

Example1: "Excuse me, could I look at your

This is a request under certain circumstances. It sounds a little bit rude because it straightforward states the request for other person to do. If you add some phrases such as "a bit", "for a while", "have a look at", etc., the tone is assuasive and sounds more polite as well.

Example2: The student asked the professor about his dissertation "Can you read it through within this week?"

This sentence is also inappropriate, because the two participants of the conversation (student and professor) have different status. If the "possibly" is added, this sentence becomes "Could you possibly read it through within this week?" The student can ease the strong influence that his words may have on the listener. Because the question is related to the "possibility" of doing something, the person being questioned feels that if he refuses, it would not seem uncooperative or rude at all.

\section{Taboo words}

Certain fields and things are taboos in the culture of all ethnic groups. EFL learners also clearly understand the existence of taboos, and they try their best to avoid words that "require extraordinary attention". However, language taboos cover a wide range both in China and the West. It seems that taboos are ubiquitous from personal life to social life. Due to the differences in historical development, social systems and values between China and the West, the content and form of language taboos are extremely different. As a result, EFL learners sometimes unknowingly commit taboos, resulting in cross-cultural communication barriers, sometimes even causing very serious consequences.

In any culture, people are constrained by the social habits from an early age. However, because of this constraint and taboo, people rarely use it in real conversations and they don't allow their children to tell the taboo words. Obviously, this has given rise to huge barriers for foreign language learners. The learners can ask teachers and ask foreign friends to resolve the ordinary problems, whereas it is tough for learners as to those taboo words. In fact, seldom can learners hear teachers talking about how to use language in daily life and neither can they find taboos from the general dictionary. Therefore, in verbal communication, foreign language learners are not willing to touch any taboos, but it is unavoidable.

Chinese culture advocates respecting the traditional virtues of the elderly. "Old" is not only the embodiment of wisdom, but also a symbol of prestige. Chinese people prefer to use the word "老" to show courtesy, respect and love, such as “您老”, “老先生 "and so on. But if these appellations with the word "old" are used in the American society, they will have the opposite effect. British and American people avoid "old" and think that "old" is synonymous with "weak, feeble and useless". They often use other words to euphemistically express the concept of "old age," such as home for adult, an adult community, senior citizens, and so on.

\section{Socio-pragmatic failure}

If one does not comprehend and neglect the social and cultural background divergences between the two participants of communication, Socio-pragmatic failure will come into forth accordingly. Tangibly, it is closely bound up with the identity of the two parties and the register of the conversation. It can be divided into the following types:

\section{Appellation}

The appellation is an important portion in verbal communication. Different appellations, on the one hand, reflect the different social status of the two sides of the communication, and on the other hand they express the speaker's thoughts and feelings towards the hearer. Proper appellation is an indispensable condition for the smooth progress of verbal communication, whereas inappropriate appellation can lead verbal communication to fail, causing unhappiness or leaving 
a bad impression. In Western society, because of its cultural orientation, social pattern, interpersonal relationship, its appellation is not as complicated as Chinese. There are only two forms of appellation: 1) "title + surname", 2) "calling its name directly". If we don't master this, the wrong appellation may be misunderstood, which has a negative impact on the communication behavior itself. For example, in china, people can call “李小明” as “李小明”, “小明”, “李先 生”, “小明先生”, “李小明先生”, “小李”. The different appellations are able to show the degree of intimacy and alienation between Chinese people. However, in English, people can only call "John Brown" as "John" or "Mr. Brown".

\section{Greetings}

Greeting is the most common way to start a conversation. Meeting and greeting someone can show courtesy, and can naturally introduce a formal conversation. As a manifestation of speech acts, greetings also reflect cultural characteristics. Deeply entrenched, the West puts the importance of individualism in all aspects: age, economic income, marital status, religious beliefs, and political beliefs are all personal privacy. Whenever you greet them with information that is inappropriate or even offensive, you will be reckoned as an impolite person. For example, the British and Americans come across and say "It's very nice to meet you!" In contrast, Chinese usually say “好久不见了, 最近忙些啥?” to greet someone, which means "I haven't seen you for a long time, have you been busy recently?" In cross-cultural communication, if you use greetings inappropriately, it often causes unexpected communication barriers. When Chinese people meet, they like to ask for their personal information: name, place of origin, age, salary, etc. The Chinese people meet on the road and ask “去哪儿?" (Where are you going?) or “吃过饭没有?” (Have you eaten?) This kind of discourse is harmony with the people interaction and does not pry into the other's privacy; however, while put into the intercultural communication, it may unconsciously invade the privacy of the other party and offend them. Therefore, when greeting foreigners, it is forbidden to use the greetings of "Chinese thought + English form" to avoid asking others' private affairs. Instead, adopting appropriate pragmatic strategies to talk about some common "safe" topics such as weather is more effective in order to avoid misunderstanding.

\section{Modesty}

Chinese culture emphasizes modesty and humility. If praised, the Chinese usually laugh at themselves. In the West, people are happy to accept praise and recognition from others. For example, a foreign teacher praised a Chinese student "Your English is very good." The student replied: "No, my English is average." In the eyes of the Chinese, the students are modest and courteous, but foreigners will feel strange and confused. The appropriate answer in the West should be "thank you" or other positive answers.

- A: You have done an excellent job.

- B: You flatter me. It's just so-so.

- A: (Embarrassed)

In Chinese, people often exploit the manner of "denial", "self-dispraise" or "self-humiliation" to show courtesy and humility, such as “哪里, 哪里”, “过奖了”, “不敢当” and so on. But if you transfer such a phrase directly into English, it is very inappropriate. The pragmatic failure of this example is that the speaker is in the absence of knowledge of expressing negation concerning congratulations, compliments and praises in English. The correct answer for praise should be: "Thanks" or "Thank you very much".

\section{Farewell}

Greeting is the beginning of the conversation, while the farewell is the end of the conversation. One of the functions of the farewell is to consolidate the social relationships between the two parties, which can be achieved by using a variety of different concluding remarks. The Chinese tend to say “你慢走”, “路上小心 ”, “你走好”, etc., translated into English as “Go slowly", "Take care". However, Westerners generally use the following language when ending conversations between the two sides: Goodbye, Goodnight, See you. According to Westerners' own notions, "walking slowly" is hard to understand. They think they don't need to go slowly because they are not old. What's more, before the formal end of the communication, both parties will send out some signals to indicate to the other party that they intend to finish. For this, the Chinese will act out to some extent, such as expressing concern for the other party. For example, "Hope you will get better soon." In most cases, Westerners only use "Thank you", "Goodbye" as a farewell. And utterances like "I have nothing to say. Goodbye.", "Go slowly, please.", "Put on more clothes" are very abrupt.

\section{ACKNOWLEDGEMENT}

In China, acknowledgments occur mostly among unfamiliar people, and family members and intimate friends generally do not say thank you in daily life; on the contrary, in the West, thanks-giving is pervasive and ordinary among family and intimate friends. In China, voicing thanks is a kind of expression of gratitude and affection; however, in English countries, not only is it a heartfelt gratitude, but it also includes politeness. This difference will give rise to communication barriers: the Chinese will feel alienation of affection among the British families and American families, while the British and Americans regard the Chinese as impolite.

In addition, the expression of the acknowledgement in Chinese is more euphemistic than the direct expression in English. Expressing gratitude in a way showing cares and apologies is a unique 
linguistic phenomenon in Chinese language and culture. The expression such as “你太辛苦了, 快歇一会儿” or inquiring after health in China is common, but in the eyes of Westerners, it is a repugnant action that interferes with their own freedom. Apologies for acknowledgment such as “麻烦您了” “给您添麻烦了” or “难为您费心了” is for the inconvenience one person's behavior brings to the other party from the other party's perspective. However, this kind of acknowledgment behavior does not make sense to Westerners, as personal contribution is just a waste of time for the other party. Understanding the differences in the expression of English and Chinese acknowledgement is conducive to reducing communication failures.

\section{Taboo topics}

The English and Chinese languages differ greatly in terms of taboo topics, mainly because the perceptions of things between them vary hugely. Differences in notions lead to pragmatic difference. Those who speak English think that others should not talk about private or taboos [3]. If the misuse of the taboo words causing the pragmatic failure is attributed to the deficient and incomprehensive linguistic knowledge of the EFL learner', the pragmatic failure caused by the taboo topic is due to EFL learners' blindness to the differences in concept. In intercultural communication, it is inappropriate to talk to British and American people about topics that involve personal life and privacy such as age, economic income, marital status, religious beliefs, political inclinations, etc. Of course, if you have to refer to these topics sometimes (such as in hotels, hospitals), you should generally explain it before the conversation. For example, in China, elders often ask questions about their descendants' personal topics to learn more about their current living conditions. However, in the UK and the US, all topics involving personal wages and savings deposits are taboos. "How much do you make?" "What's your income?" "How much did that dress cost you?" "How much did you pay for that car?" These questions are not appropriate.

\section{Reasons for pragmatic failures in intercultural communication Cultural difference}

Linguists have conducted extensive investigations and analysis of the causes of crosscultural pragmatic failures. After careful and comprehensive research, it can be found that the occurrence of cross-cultural pragmatic failures is more due to cultural differences. It is mainly manifested in values, ethics, and ways of thinking.

Each culture has its own unique cultural norms and values. Western culture is "I-oriented" stressing the individual value, thus leading to a high degree of respect for the personal privacy of Western society. On the contrary, Eastern culture is "We-oriented" with collective value as the priority (collectivism), emphasizing on harmony in interpersonal relationships. Therefore, in cross-cultural communication, if Chinese foreign language learners neglect the privacy of Western society and talk about taboo topics, it is easy to cause pragmatic failures.

Morality is an organic element of social culture, and the difference in moral values is also one of the main reasons for the failure of intercultural communication. In China, Confucianism dominates ethics, stressing the importance of etiquette, which makes people gradually regard the humility of treating others as human creed and noble virtue [10]. In crosscultural communication, the Chinese deliberately devalue themselves and fundamentally praise others in the spirit of courtesy and modesty. While in the West, the development and realization of personal interests has become the starting point and general purpose of their morality. Therefore, differences in expression of modesty and acknowledgment have caused sociopragmatic failure.

Significant differences in thinking patterns directly affect Chinese and Western verbal expression. The traditional Chinese way of thinking focuses on direct and intuitive experience, and Chinese people like to know the internal essence from the whole by intuition. Chinese tend to think in a roundabout way, but westerners like to think straightforwardly because they pay more heed to logic. If the Chinese way of thinking can be reflected by spiral or wavy curve, then the Western way of thinking can be represented by a straight line. As a result, the style or manner of speaking is absolutely different in intercultural communication.

\section{Negative language transfer}

People with different cultural backgrounds have different speaking protocols and habits. These conventions and habits are generated from daily life and are difficult to change. Therefore, when learning English, learners can easily apply Chinese expression habits to English, especially everyday language, which forms a wrong transfer of the mother tongue. The negative language transfer can be showcased in the following three aspects:

The first aspect is culture. Cultural migration refers to cultural interference caused by cultural differences, which is manifested in intercultural communication or foreign language learning. When students learn English, they will inevitably be influenced by thinking and habits of their mother tongue. They will subconsciously use their own cultural norms and values to guide their words and deeds and thoughts, and use this as a standard to judge other's words and deeds and thoughts. This has lead to obstacles for EFL learners to learn English, which has formed a negative cultural transfer [11]. 
Language itself is the second aspect. Pragmatic failures are reflected in all levels of language. At the syntactic level, learners are apt to ignoring the differences between English and Chinese language structure, expressions and cultural connotations, not knowing the corresponding and customary expressions of English in specific situations, mistakenly using native language expression structures or misunderstanding English in communication. On all these occasions, on no account can they effectively express their own thoughts and intentions, and even produce misunderstandings [12].

Lastly, in terms of speech acts, there are differences in the expressions of speech acts such as greetings, salutations, requests, invitations, compliments, and apologies in English and Chinese. In intercultural communication, Chinese EFL learners are prone to "mistaken equal Chinese vocabulary to English one by one". They think that English vocabulary is completely equivalent to Chinese in terms of cultural connotation and extension, and mistakenly introduces Chinese usage habits into corresponding intercultural communication scenarios [12]. If people always use their own cultural pragmatic rules or pragmatic habits to explain the expression of the other's speech acts, it will lead to socio-pragmatic failure.

\section{Improper classroom teaching}

Our teaching has not yet consciously, systematically and fully reflects English pragmatic rules and culture. This blank in teaching makes it possible for students' mother tongue to interfere. The language teaching content in the primary stage (the meaning and cultural connotation) is often simple and rough. However, the ideas that adults want to express are complex and subtle. The two form a contradiction between them, which is a source of pragmatic failure [13].

The main problem in teaching is that the focus of teaching stays in the teaching and learning of language knowledge and structure for a long time, ignoring the differences in language use caused by social functions such as language function and context. Many English learners possess grammatical and discourse skills, but lack pragmatic and communicative skills [14]. In addition, on account of the influence of behavioral psychology, English teaching emphasizes on practicing spoken English again and again. Students are required to learn to use complete sentences to give complete information. However, the use of complete sentences is limited by context. In other words, not every moment of communication requires the speaker to say a complete sentence. Sometimes a complete sentence will appear to be inappropriate and cause communication failures. Some inappropriate teaching methods may have a negative impact on foreign language learners, and even pragmatic language errors in cross-cultural communication.

\section{Lack of authentic English communication opportunities}

The best way to learn a foreign language is to let foreign language learners immerse themselves in the atmosphere of the target language culture and directly contact the native language speakers. However, the objective fact is that there are a large number of English learners in China, most of whom could not have the opportunity to experience the foreign culture in the target language country. They all learn foreign languages in their own cultural atmosphere. When a person is born, he begins to accept the influence of his own culture. His own culture is deeply rooted and his words and deeds are totally affected. Moreover, classroom learning does not meet the needs of most foreign language learners. They rarely have the opportunity to interact with native English speakers, lack the opportunity to learn authentic English, lack sufficient knowledge of English-speaking countries and use English in practice. Due to the lack of practical use opportunities, it is naturally impossible to speak the appropriate language in appropriate situations, and the probability of cross-cultural mistakes increases.

\section{Suggestions for avoiding cross-cultural pragmatic failures}

Foreign pragmatics expert Tyler [15] once pointed out: "In interaction with foreigners, people who speak native language are generally more tolerant of language and grammatical errors. However, violation of the rules of speech is often considered as rudeness." Pragmatic failures of Chinese EFL students in crosscultural communication are bound to hinder students' interaction with foreigners. The integration and interaction of Chinese and English languages and cultures can bring about the benign results of " $1+1>$ 2 ". In order to overcome the pragmatic failures in intercultural communication, improve the sensitivity to the target language culture, and improve their social and cultural capabilities, we should take countermeasures from the following aspects:

\section{Establishing the concept that language learning is cultural learning}

Language and culture are interconnected: language reflects culture, culture infiltrates into language [6]. Learning language must be closely linked with learning culture, and it is impossible to separate language from culture. In the process of promoting our own national culture, we must learn and respect foreign culture. Not only do we need to understand the literal meaning of a word or phrase, but also need to master its profound cultural connotation and grasp how to use it. Any inaccurate use of English literally or abuse is inadvisable.

\section{Enhancing sensitivity and comprehension of the target language culture}

For Chinese foreign language learners, it is the best way to acquire foreign language culture knowledge by reading extensively and accumulating the knowledge gradually. Only by reading a large number of original 
English books, magazines, and novels, can you truly understand the delicate differences between Chinese and Western cultures, and thus specifically know when, where, and what to say in English. These measures can help students effectively avoid cultural interference in communication and enhance social and cultural capabilities.

\section{Improving grammatical, pragmatic and social language skills}

Chinese EFL students should learn grammar knowledge, pragmatic knowledge, and reduce communication barriers caused by grammatical errors and pragmatic transfer. It is of great help to learn social and cultural knowledge and enhance social language skills. At the level of discourse, because of the cultural differences between different countries, the social meanings of the language forms they use are also different, so recognizing and distinguishing between Chinese and foreign cultural backgrounds is conducive to correctly use language. It is also useful to be familiar with the living habits of people speaking English, including the habit of talking. Otherwise, it may cause misunderstanding and unpleasantness, although students can speak English without grammatical mistakes. Therefore, students must actively participate in the practice of intercultural communication and enhance social language ability.

\section{Cultivating intercultural communication skills}

American linguist Douglass Brown [16] said that "the highest level of learning language is not simply mastering the language form, but completing the communicative function of the language." The purpose of learning language is efficient and effective communication. Only through extensive language communication and practice, can we accurately use the language to understand the "communicative culture", so that pragmatic competence and language ability can be fully combined to form a consummate communicative competence. Participating in "English Corner", "English Salon", evening parties and debates, and maintaining more contacts with foreign teachers are effective means to improve intercultural communication skills.

\section{CONCLUSION}

On account of the existence of cultural differences, it is inevitable that Chinese students encounter with obstacles and even conflicts in the process of intercultural communication. This article analyzes two kinds of pragmatic failures from the perspective of intercultural communication, and summarizes the various reasons of pragmatic failures in intercultural communication. It can be found that the occurrence of cross-cultural pragmatic failures is more due to cultural differences. Therefore, in order to successfully and effectively achieve intercultural communication, Chinese EFL learners should enhance their cultural awareness, improve their sensitivity and understanding of English language and culture, improve cross-cultural communication skills, and develop communication skills.

\section{REFERENCES}

1. Thomas, J. (1983). Cross - cultural pragmatic failure. Applied Linguistics, 4(2): 91-112.

2. Leech, G. (1983). Principles of pragmatics. London: Longman.

3. Ziran, He. (1988). Introduction to Pragmatics. Changsha: Hunan Education Press.

4. Mei, Meng., \& Qinliang, Liu. (2000). On college students' English pragmatic competence. Journal of Xi'an International Studies University, 4: 92-94.

5. Xuemei,Wang. (2006). On the gender differences of EFL's language ability and pragmatic competence and its teaching implications. Foreign Languages and Literature, 1:29-33.

6. Baohong, Gao. (2003). Cultural cognition in communicative foreign language teaching. Foreign Language and Foreign Language Teaching, 8: 3335.

7. Jiawei, Lu. (2013). The role of classroom pragmatic teaching in the cognitive framework on the development of learners' second-language pragmatic competence. Journal of PLA University of Foreign Languages, 1(1):67-71.

8. Zhanhao, Jiang., \& Baoguo, Zhou. (2012). On learners' pragmatic competence evaluation. Foreign Language Teaching, 1(5): 45-48.

9. Gass, S., \& Selinker, L. (Eds.). (1992). Transfer in language learning (Revised edition). John Benjamins.

10. Zongyi, Du. (2013).On the differences and exchanges between Chinese and Western cultures. Beijing Social Sciences, 2: 23-27.

11. Muchun, He. (2018), On college English classroom teaching strategies based on cultural begative transfer. Education Theory and Practice, 38(09): 55-56.

12. Wei, Meng., \& Xiaoling, Zhou. (2011). On pragmatic failures in intercultural communication. Academic, 7:179-186.

13. Chang, Y. F. (2010). "I no say you say is boring": The development of pragmatic competence in L2 apology. Language Sciences, 32(3):408 -424.

14. Yongping, Ran. (2013). Pragmatic in English learning in multi-context. Foreign Language Teaching and Research, 5: 660-680.

15. Tyler, A. (2012). Cognitive linguistics and second language learning. New York: Routledge.

16. Douglas Brown, H. (2014). Principle of language learning and teaching (6th Edition). Pearson Education ESL. 